\title{
A Soft Computing Approach to Quality Evaluation of General Chemistry Learning in Higher Education
}

\author{
Margarida Figueiredo, José Neves and Henrique Vicente
}

\begin{abstract}
In contemporary societies higher education must shape individuals able to solve problems in a workable and simpler manner and, therefore, a multidisciplinary view of the problems, with insights in disciplines like psychology, mathematics or computer science becomes mandatory. Undeniably, the great challenge for teachers is to provide a comprehensive training in General Chemistry with high standards of quality, and aiming not only at the promotion of the student's academic success, but also at the understanding of the competences/skills required to their future doings. Thus, this work will be focused on the development of an intelligent system to assess the Quality-of-General-Chemistry-Learning, based on factors related with subject, teachers and students.
\end{abstract}

Keywords General Chemistry ' Higher Education ' Logic Programming • Knowledge representation and reasoning $\cdot$ Artificial Neural Networks

M. Figueiredo

Departamento de Química, Centro de Investigação em Educação e Psicologia,

Escola de Ciências e Tecnologia, Universidade de Évora, Évora, Portugal

e-mail: mtf@uevora.pt

J. Neves $(\square) \cdot$ H. Vicente

Centro Algoritmi, Universidade do Minho, Braga, Portugal

e-mail: jneves@di.uminho.pt, hvicente@uevora.pt

H. Vicente

Departamento de Química, Escola de Ciências e Tecnologia,

Universidade de Évora, Évora, Portugal

C Springer International Publishing Switzerland 2016

M. Caporuscio et al. (eds.), mis4TEL,

Advances in Intelligent Systems and Computing 478,

DOI: 10.1007/978-3-319-40165-2_9 